\title{
English as Tyrannosaurus rex
}

\author{
JOHN M. SWALES*
}

\begin{abstract}
The increasing domination of English as the world's leading medium of international professional communication has begun to impact English for Academic Purposes programs. Specifically, questions arise as to whether English is becoming too successful. This paper reviews several of the resulting ideological challenges to EAP. Although not all of these challenges are accepted as well-founded, the paper argues that resistance to the 'triumphalism' of English is also a responsibility of EAP teachers. This resistance can be encouraged by further research into the academic registers of languages other than English, by support for local-language scholarly publications, and by using the current controversies as consciousness-raising exercises in EAP classes for international graduate students.
\end{abstract}

\section{INTRODUCTION}

The tone of this essay is somewhat reflective, indeed in part self-reflective. As it happens, since the middle 1960s I have been an active member of what has become known as the English for Academic Purposes (EAP) movement, wherein I have been busy enough as program administrator, journal editor and research student advisor, and as a long-service teacher, talker and writer. Reflecting on these extensive activities reveals certain recurrent themes, two of which are relevant to this paper. One has been an attempt to try and make theory and practice work together to mutual advantage, primarily by basing pedagogical recommendations and decisions on the best understanding we can reach of how some real communicative world works. This then has been a long-standing commitment to linguistic, discoursal and generic analyses. The second and orthogonal tendency has been to feel that the EAP movement tends to rely on a rather narrow range of canonical texts in such areas as systemic linguistics, needs analysis and corpus studies, and thus is prone to ignore important work in areas such as anthropology, sociolinguistics, rhetoric and social theory. The wider body of work usefully raises as many questions as it usefully provides answers and insights.

The above account of a working life could be seen as one very small part of the story of efforts around the world to help non-native speaker students, scholars and researchers survive and then flourish in increasingly Anglophone academic and technical environments. As the EAP movement would likely tell it, this narrative would be a mostly Whiggish history of solid advance and achievement, since it is one marked by tremendous growth in the money spent on it, and in the amount of materials, research papers and conference talks generated by it (Phillipson, 1992). While it remains true that institutional attitudes to the EAP field continue to be problematic, especially in more prestigious centers of higher education, today problematization seems to have moved from the administrative background to the curricular center, and from there toward some questioning of the nature of the EAP enterprise itself. More specifically, certain questions that, at least for me, have remained buried under the pressures of getting on with unpretentious but perhaps useful

\footnotetext{
*English Language Institute, University of Michigan, 2001 N. University Building, Ann Arbor, MI 48109, USA. E-mail: jmswales@umich.edu
} 
service work, have now come to the surface. These are issues that applied linguists in the EAP movement need to be concerned about, none more fundamental than the issue of whether English is becoming too successful. This is the 'English as Tyrannosaurus rex' of this essay's title - English as a powerful carnivore gobbling up the other denizens of the academic linguistic grazing grounds.

\section{IDEOLOGY AND ENGLISH FOR ACADEMIC PURPOSES}

Such issues have been most prominently raised in such works as Phillipson's Linguistic Imperialism (1992) and Pennycook's The Cultural Politics of English (1994), and in articles by Santos (1992) and Benesch (1993) that criticize ESL, particularly ESL writing, as timidly avoiding ideological issues and refusing to engage in critical pedagogy. EAP practitioners are therein accused of being variously 'accommodationist,' 'assimilationist,' or 'quietist.' Are these charges well-founded and, if so, what needs to be done to rectify the situation? A possible starting point for a response - at least for me - is the following sentence from Genre Analysis that has apparently become something of a call to arms to those whom Allison (1996) describes as being of an 'ideologist' persuasion: 'in the case of discourse community and genre, for instance, I shall not consider differences that arise as a result of differing ideological perspectives . . such as those found in the work of neo-Marxist and capitalist economists . . ' (1990: 9). In response to my critics, I could, of course, begin by observing that I was in no way denying that such differences may and do exist - quite the contrary, in fact. Rather, in trying to map out academic tribes and territories (Becher, 1989) for nonnative speakers, as a kind of discoursal diaspora, and especially for international graduate students beginning a course of study, decisions have to be made about the appropriate scale of that map and about how much detail to include. As a functional linguist, for example, I have the following category set - as one of many - available: linguists, text linguists, systemic text linguists, the Sydney School, Jim Martin. When discussing matters with likeminded colleagues, we might indeed want to talk about differences between the views of Jim Martin and Michael Halliday. With my upper-level undergraduates, taking a discourse analysis class, 'systemic text linguists' looks like the right level. On the other hand, responding to a neighbor's incidental query as to what I do at the university, 'linguists' tout court seems right. One key element in audience-design, in real life and in pedagogical contexts, is calculating an appropriate level of specificity and detail.

That said, certainly I erred strategically by opting for a Marxist example, and erred rather more substantially - in reflecting on my own institution where, as far as I know, there are about one-and-half token socialists in a total economics faculty of over 50 . Doubtless, the situation may be very different in different institutions and different countries. Certainly, there will be circumstances when the ideological/epistemological/ methodological variable will be a necessary and key ingredient in understanding the texts of a self-defined disciplinary community. Anthropology would seem a good contemporary example of such a tormented landscape. In a New York Times book review for May 7 , 1995, Nancy Scheper-Hughes reviews Clifford Geertz's (1995) professional memoir under the title and sub-title of 'The end of anthropology: Clifford Geertz reflects on a much reduced science.' In it, she writes:

In the apt phrase of Renato Rosaldo, an anthropologist at Stanford University, the museum notion of cultures as timeless, sacred and highly organized gave way, with some help from Mr. 
Geertz, to the idea of culture as a garage sale - spontaneous, profane and chaotic. A truer image, perhaps, but a bitter pill for many to swallow (p. 22).

This issue of how we might deal, as instructors, with disciplinary turbulence and interschool conflict is a very serious one, since it involves all of us reflecting upon which groups of our students are 'ready' or 'not ready for exposure to the revelation that the academic terrain they are attempting to map is ideologically and academically contested ground. However, in this reflective process, we might do well to remember there may well be circumstances where what we might call 'conflict variables' have a much more subdued profile, at least on the surface. A study, for instance, of the systematic botanists in an important university herbarium (Swales and Luebs, 1995) showed a largely untroubled world of ancient traditions and agreed standards of scholarship with immensely deep timelines. In fact, the one major current controversy in the field is in fact amazingly characteristic of its conservatism: whether the Linnean tradition that the opening paragraph of all descriptions of species new to science should continue to be written in Botanical Latin.

Thus, distinctions between marxist/capitalist, feminist/traditionalist, qualitative/quantitative, formal/functional, disciplinary/interdisciplinary, researcher/clinician (Schryer, 1994) will have greater or lesser salience in particular arenas, and so would, in consequence, have greater or lesser significance for our support courses. While I am grateful to my critics for helping me to re-think this, I remain of the view that pragmatism is open to ideology when ideology is salient - even though making any such judgement of salience is itself a complex matter. As Mauranen pertinently observes, 'from a dominant position, in any field, it looks as if things are not ideological, while from a dominated position, it looks as if they are, and that ideology is highly salient' (p.c).

In fact, the EAP movement is itself well aware of such disparities from its own perceptions of English-medium institutional attitudes to non-native speaker students themselves. Here are just two of such socio-political stances (the first I owe to Janopoulos (1995)).

Sink or Swim/No Mollycoddling. 'If NNS have special problems, then they have to fix them on their own; let them go to a private language school or a community college for this, or get a tutor or hire an editor. Their problems are not our problems.' (Oxbridge, the Ivy League, and now, if I read the newspapers aright, the New York and California university Systems).

Benefit of the Doubt/It will all Turn Right in the End. A faculty view which says 'I can't really understand what this NNS has written, but as far as I can see she seems to know what she is talking about, so I will give her the benefit of the doubt.' Sounds familiar? This recipe for the ghost-writing of theses, projects, reports and dissertations? This reluctance to admit to what needs to be done to make NNS writers independent, voiced, and rightfully proud owners of their texts? (A view, in my experience, ironically much more common among humanities faculty than those situated elsewhere.)

Neither of these positions is exactly innocent of ideology, representing as they do the anti-entitlement republican and the liberal democrat. And most of the EAP people I know (apart from the dispirited and faint-hearted) fight against them. Indeed, the history of EAP has been mostly assertive, innovative and oppositional - as a counter-ideology - in defence of both its underprivileged status and its somewhat marginalized constituency. Consider, for example, EAP's advocacy of the following: 
- The importance of language and communicative skills in academic study.

- The value and merit of action-research.

- The fact that NNS students often have underlying strengths which offset apparent weaknesses. (In my institution, across the board, international students gain doctoral degrees faster and with a lower drop-out rate than domestic ones.)

- The importance of the Sisyphean task of educating and re-educating faculty and administrators. (Especially as 99 percent of the time any change in the senior administration means an increase in ignorance about the EAP operation.)

However, these politics of tempered and local resistance seem no longer sufficient in a geolinguistically changing world. The bigger and more interesting question is the issue of English itself, as the Tyrannosaurus rex of the linguistic grazing ground, and what influence that might have on our classroom roles, especially for those of us who teach NNS senior graduate students, visiting scholars and faculty.

\section{TRIUMPHALIST ENGLISH}

While a leading cultural anthropologist of our time closes an illustrious career in wry, tempered and perhaps evasive resignation, as if he had lived through a Golden Age into a Silver One, a leading sociolinguist of our time, Joshua Fishman, comes toward the close of his with a renewed activist vigor. Nothing signals this more clearly than the title of his 1991 volume Reversing Language Shift: Theoretical and Empirical Foundations for Assistance to Threatened Languages. In this book Fishman takes on the jeremiahs who lament that 'It is too late,' or 'nothing can be done' to save dying languages by unequivocally expousing 'the right and ability of small cultures to live and inform life for their own members as well as to contribute thereby to the enrichment of humankind as a whole' (1991: 35). As we might expect, a strong subtext is a human variant of the well-known arguments for preserving global biodiversity. Key for Fishman is 'fostering intergenerational mother tongue transmission' (1991: 5) as a nurturing mechanism, as a cultural right, and as a resource for society in general.

However, my appropriation of Fishman's marriage of scholarship and social responsibility is side-shifted, because I want to move the concern to another area more directly relevant to my own occupations and preoccupations. This is not the loss of languages per se, but the loss of specialized registers in otherwise healthy languages as a clear consequence of the global advance of English. This advance is taking many forms, and has been much investigated (see Kachru, 1994, for a synopsis) so the treatment here of the relevant phenomena will be highly selective. In a recent Scientific American, Wayt Gibbs, in an article entitled 'Lost science in the Third World', calculates that in 1994 no less than 31 percent of all papers published in mainstream journals emanated from the USA. Japan was next with only 8 percent. Sample percentages from countries with large university systems are: Brazil, 0.6 percent, and Mexico and Egypt with around 0.3 percent. Such wrenching disproportions thus structurate (Giddens, 1984) America's role as the global academic gate-keeper. Second, the trend to English (in whatever 'nuclear' or 'interlanguage' form it manifests itself) is accelerating as computer-mediated developments such as the World Wide Web accelerate. Third, this trend continues to be reported in largely triumphalist terms by anglophone commentators, who continue, for example, to poke fun at efforts by the French government to maintain both the viability of the French language and its historically Gallic character. In 1995, my local newspaper carried an 
Associated Press report from Paris which opened with one of those familiar military metaphors:

As French government officials fight the invasion of English words like 'airbag' and 'software,' a new survey reports that they may be losing their army.

Nearly 71 percent of French speakers welcome the entry of foreign words into their language, according to a survey published Friday in the newspaper Le Figaro. (Ann Arbor News, March 3, 1995)

Fourth, valiant and interesting attempts by critics like Phillipson and Pennycook to undermine this triumphalist rhetoric by relating it to new manifestations of neocolonialism, to the consumerist marketing of English as a 'worldly' global commodity, now seen as the lingua franca of the 'haute bourgoisie' around the world, or to the defence of socio-political structures that rely on linguistic overclasses and underclasses for their survival, will likely fall on deaf ears in the Anglophone majoritarian cultures, however much their criticism may be discussed and appreciated in smaller speech and discourse communities around the world. John Honey, for example, admittedly representing a very different part of the political spectrum, ends his review of Phillipson's Linguistic Imperialism as follows:

Its main value is in forcing those who teach English and those who theorise about the forms of the language to re-examine the bases of their own convictions about the function and value of their work. It has certainly reinforced mine. (p. 121.)

I am not so sanguine. Indeed, I have belatedly come to recognize a certain selfdeception in my 30-year involvement with English for Academic Purposes. Certainly in the 1970s I accepted the position which argued that what Third World countries needed was a rapid acceleration in their resources of human capital, which could be achieved by a hurried transmission of Western technical and scientific know-how delivered through the medium of English and supported by appropriate EAP programs. I also believed that working overseas in scientific English, as researcher, materials writer and teacher, was, in essence, a culturally and politically neutral enterprise, and thus one somehow distinct from the oftentimes-quaint efforts of the British Council, USIS, The Alliance Francaise and the Goethe Institute to promote the glories of their national cultures in unlikely exotic and underprivileged venues. In doing so, I conveniently overlooked the links between the teaching of technical languages and the manufacture and export of technical equipment. So, when I read, say, Phillipson's counter-culture account of how British ESL created an academic and commercial base for itself, I find myself caught up in some serious reflection. I now see how ESP's 'accommodationist' and 'technocratic' stance about the value of English as a wider window on the world has paved the way for the enormous resources that, both publicly and privately, have accrued to ESL. And one favorite quote comes from the opening page of Richard Bailey's Images of English (1991). It is from a Pakistani commentator: 'Teaching English has become a multimillion-dollar business the world over, a lucrative business next only to drug trafficking' (1991: 1). I confess I am taken, when reading of the pent-up demand for English in places like Eastern Europe, China and Vietnam, by the implication that the more crassly commercial interests in ESL are running enterprises dangerously close to language trafficking. 


\section{SPECIAL REGISTERS IN ENGLISH AND OTHER LANGUAGES}

With that as setting, let me now return to the question of specialized registers, and why we might pause a little to reflect upon their erosion as the world's first century of English dominance comes toward its close. In some areas, registral biodiversity seems secure. The special varieties of language that have evolved to structurate religious practice, especially through the genres of sacred texts and religious services, particularly when supported by indigenous religious educational institutions, would seem largely immune to being overtaken by English, if only because the world's religious belong to such a wide range of age groups and social classes. Another protected area would seem to be the law since the law (colonial legacies aside) has very much been a history of national development divorced from international engagements. Fredrickson (1996), for example, is able to show that Appeals Court documents in a Swedish province and a US state are substantially different in their length, citational uses, and patterns of intertextuality in consequence of differences in traditions of court procedure, in the varying authority of precedent, and in the different weights given to written and oral legal arguments. She can show, for example, that in the discourse among the legal parties, in Sweden the non-local or case-extrinsic argument is embedded in the local one, while in the USA the local arguments are embedded in wider consideration of what the law might have to say per se. Such differences will likely endure.

However, as we know, it is in other areas such as the media (film, theater, television, pop music, radio, print journalism) that the concern about English domination is greater. It is doubtful, for example, whether a recognizedly world-class Swedish-language oeuvre like that of Ingmar Bergman's will be possible in the next half-century. Apart from these areas, there is also growing concern about register loss in the world of scholarship. There are several aspects that need to be considered. First, there are the attempts being made to create and foster modern scientific varieties of languages - what Philippino scholars Gonzalez and Battista call 'edulects' (quoted in Honey, 1994); more specifically, the attempts to nurture scientific or academic varieties of languages such as Swahili, Arabic, Bahasa Melayu, Hebrew and Pilipino. We can note that these are all non-Western languages with their principal homes below the Mediterranean or below the Equator, and thus a case can be made for their support for reasons of addressing North-South imbalance alone. Of course, the evolution of such registers is fraught with difficulties. To our shame, one is a relative lack of interest in them on the part of linguists and applied linguists. Another is the well-attested tendency of off-center scholars to try and publish 'their best in the West,' offering more minor works for local publication. A third, and relatively new trend, is for promotion in Third World countries (and many others) to become much more directly tied to publication in international refereed journals. This is by no means inevitably a sensible policy, because, in some fields, perhaps most crucially in agricultural and ecological sciences and in preventive medicine, the advantages of developing local research and publication traditions is clearly of benefit to many parties, from government ministers, to those concerned with environmental issues, to agricultural extension officers.

Ahmad (1997) investigates the current status and character of scientific Malay (Bahasa Melayu). She finds support for Fredrickson and Swales's (1994) observations that small research communities (in their case Swedish linguists) do not need to write competitive create-a-research-space-for-yourself introductions, as described in Swales (1990). In the Swedish case, there was apparently a greater pressure for constructing opening texts that 
would attract as much of a very limited readership as possible, in the Malaysian context, Ahmad additionally ascribes the avoidance of negativism in article introductions to the structure of Malaysian higher education, whereby each university is given a specialized role. As a result, a member of the single department of fisheries in the country may well be chary of climbing up on the backs of his or her only local colleagues and collaborators. These studies suggest that small discourse community size (and its local distribution), rather than rhetorical tradition per se, may be a prime mover in an alternate rhetoric of a looser and gentler kind. Following the lead of Hinds (1987), Eggington (1987), Kachru (1995) and others, Ahmad builds a non-deficit model for article introductions in small discourse communities which more truly and accurately reflects the rhetorical concerns of such writers. Such initiatives are particularly welcome as 'a legitimate activity for fostering cross-cultural understanding via an appreciation of cultural differences' (Kachru, 1995: 182). However, even if the applied linguistics' world is beginning to make a more proactive and pluricentric effort to understand alternative academic and scientific traditions of scholarship, there is still a pressing need for some transfer of resources, both material and intellectual, to support well-conceived local scholarly publication initiatives in the first place.

A rather different scenario is emerging in Scandinavia, where the preservation of academic registers, rather than their creation, is matter of considerable concern and debate. In Sweden, for example, the last journal to publish original medical research in Swedish has recently gone over to an all-English policy. At present, the only Swedishlanguage medical serial is entitled Läkartidningen, or 'Doctor's Newsletter,' a semipopularized round-up of research news and other events. The full written medical register looks lost. One possible response is to adapt Fishman's 'fostering intergenerational mother tongue transmission' to 'fostering academic intergenerational register transmission' whereby older scholars, as practised and fluent users of threatened registers, undertake greater responsibility in helping younger ones acquire these special languages. While, of course, there may be dangers here of quasi-archival preservation of traditional styles, I believe these can be lessened if the enterprise is entered into in a spirit of cross-generational collaboration and seen as a means of actually enlivening and expanding native scholarly language registers. Again, we need to encourage research and development programs for academic languages other than English.

The loss of professionally-marked registers has several fairly obvious consequences and some less obvious ones. One of the latter is the loss of professional speech differentiation for the purposes of literary characterization, for entertainment and for parody. If nobody talks and writes any more like a medical professor or a research scientist, or even an avantgarde critic, because all these roles are now occupied by English, then creative national culture is itself impoverished. While I suppose that nobody would question that religious scholars need to know the languages, such as Sanskrit, Hebrew, New Testament Greek and Arabic, wherein the founding texts were originally created, nobody seems to recognize that Swedish has actually been the vehicle for much of this century for articulating the most developed forms of social democracy and the welfare state, or that, as Grafton (1994) has brilliantly showed for history, it is German scholarship that has elaborated and maintained the persuasive rhetorical device of the footnote, and as Clyne (1987) has suggested, it is German that has developed the Exkurs, inevitably and pejoratively glossed in English, as 'digression.' Ongstad, himself a Scandinavian, has observed that when a culture starts to lose its genres, it begins to die (Ongstad, 1992). As for those who would argue that fighting 
against an inexorable trend is just naive sentimentalism, there is Mauranen's 'cultural rainforest' argument to parallel Fishman's: 'Insofar as rhetorical practices embody cultural thought patterns, we should encourage the maintenance of variety and diversity in academic rhetorical practices - excessive standardization may counteract innovation and creative thought by forcing them into standard forms' (Mauranen, 1993b: 172).

Mauranen's back-up strategy is to accept that, in her case, scholarly writing in Finnish is not likely to long survive outside of various kinds of Finnish studies themselves. But does this mean, she asks, that if we have to use English for academic publications, we have to use it just like the anglophones? Her own research shows that Finnish rhetoric differs considerably from Anglo-American rhetoric, being more implicit, being more poetic, being less-inclined to market its text metadiscoursally, and so on (Mauranen, 1993a). Should we not try, she argues, to preserve our Finnish rhetorical traditions in another and much more widely distributed tongue? And how can we persuade the majoritarian Anglophone cultures to accommodate our concerns and thus accept rhetorical - if not linguistic diversity? While there are again many questions that arise about the transference of cultural traditions in this way and what indeed might be preserved within the matrix of another language, Mauranen's arguments should cause us to reflect soberly on anglophone gate-keeping practices. Gate-keepers would no longer be able to get away with saying that 'these foreigners just don't know how to frame issues and arguments in ways that we feel comfortable with,' because those foreigners would no longer be trying to do those things in the first place.

\section{EDUCATIONAL IMPLICATIONS}

As might be expected, a number of the foregoing reflections and concerns leak into my educational practice. My current main EAP activity is as teacher of my institute's two most advanced writing courses: Research Paper Writing; and Thesis and Dissertation Writing. These courses carry graduate credit and consist of NNS volunteers who come from all across the university. To my surprise this heterogeneity has turned out to be a great advantage. In contrast to what I know of most other advanced writing courses, in my case there is no shared content, no shared outside courses, no shared methodology and little direct competition among the participants. In consequence, everybody soon realizes that the one thing that we do share is an interest in rhetoric and discourse in all its diverse academic manifestations. The general orientation of these courses is well captured by Belcher and Braine's introduction:

The approach to demystification of Anglophone academic discourse is . . neither a sociotherapeutic one of open resistance to academic oppression ... nor a psychotherapeutic approach committed to helping students find some 'unified or stable subjectivity'. It is, rather, an approach informed by a belief in the power of explicit cognitive awareness of the texts, subtexts, and contexts of academic discourse to enable individuals to join collectivist endeavors that academic communities are without loss of the 'home perspectives' that Bizzell . . . has often spoken of (1995: xv).

In order to throw light on 'home' and 'away' perspectives, the courses spend time on many of the issues and people referred to in this essay. We look at different academic traditions around the world, especially in terms of criticism, tropes of citing practice, author-reader relationships and the like. We discuss exemplars of what I have elsewhere called the 
'occluded' or hidden genres of the academy (Swales, 1996), such as applications, recommendations, and referees' critiques. We explore case histories of student academic success and failure (e.g., Belcher, 1994). We see what can be learned from academic parody and humor. And we look at what is involved in making their first moves toward establishing their academic credibility with an audience wider than their individual class instructors or advisors. Much of this is then as much concerned with the soft underbelly of the academic process as it is with the hard carapace of its polished product.

Although, like Lemke (1994), I believe that knowledge of any genre is best viewed as a strategic resource, genre is not the only shot in the strategic locker. At least for my sophisticated senior graduate students, equally resourceful or resource-rich are discussions of anglophonicity and its insidious spread; of the causes and effects of being members of small and large academic discourse communities; and of the histories of different rhetorical traditions (as in Bloch and Chi's (1995) study of Mandarin citation patterns). This is not, pace my critics, a revolutionary ideology; nor is it a critical pedagogy in the sense that I understand the term. However, I would like to suggest that the approach is a kind of liberation theology, especially if it frees my students from the overarching dominance of anglophone native-speakerism, from consuming attention to the ritualistic surfaces of their texts, from an authoritative and received world view of academic and technical text as 'objective,' and from a dependence on imitation, on formulas, and on cut-and-paste anthologies of other writers' fragments. Beyond all this, there is one final aspect that increasingly engages my attention, not so much as a writing instructor, but as a linguist. I try to turn discussion to what linguistic responsibilities my participants might have as future significant participants in their non-linguistic fields of expertise. If there is rhetorical consciousness-raising about the academic language issues, such as the contemporary power imbalance of an instrumental carnivore amok on a plain of sentimental herbivores, then precisely what would they, not me, want to do about it?

\section{REFERENCES}

Ahmad, Ummul K. (1997) Scientific research articles in Malay: a situated discourse analysis. Ph.D. Dissertation, The University of Michigan.

Allison, Desmond (1996) Pragmatist discourse and English for Specific Purposes. English for Specific Purposes, 15, 85-104.

Bailey, Richard W. (1991) Images of English: a Cultural History of the Language. Ann Arbor, MI: The University of Michigan Press.

Becher, Tony (1989) Academic Tribes and Territories. Milton Keynes: Open University Press.

Belcher, Diane (1994) The apprenticeship approach to advanced academic literacy: graduate students and their mentors. English for Specific Purposes, 13, 23-34.

Belcher, Diane and Braine, George (eds.) (1995) Academic Writing in a Second Language. Norwood, NJ: Ablex.

Benesch, Sarah (1993) ESL, ideology and the politics of pragmatism. TESOL Quarterly, 27, 705-716.

Bloch, Joel and Chi, L. (1995) A comparison of the use of citations in Chinese and English academic discourse. In Belcher and Braine (1995: 231-274).

Clyne, Michael (1987) Cultural differences in the organization of academic texts. Journal of Pragmatics, 11, 211247.

Connor, Ulla and Kaplan, Robert B. (eds.) (1987) Writing across Languages: Analysis of L2 Text. Reading, MA: Addison-Wesley.

Eggington, William A. (1987) Written academic discourse in Korean: implications for effective communication. In Connor and Kaplan (1987: 153-168).

Fishman, Joshua A. (1991) Reversing Language Shift: Theoretical and Empirical Foundations of Assistance to Threatened Languages. Clevedon, UK: Multilingual Matters.

Fredrickson, Kirstin M. (1996) Contrasting genre systems: court documents from the United States and Sweden. Multilingua, 15, 275-304.

Fredrickson, Kirstin and Swales, John M. (1994) Competition and discourse community: introductions from 
'Nysvenska Studier.' In Text and Talk in Professional Contexts. Edited by Britt-Louise Gunnarsson et al. Uppsala: ASLA. pp. 9-22.

Geertz, Clifford (1995) After the Fact: Two Countries, Four Decades, One Anthropologist. Cambridge, MA: Harvard University Press.

Giddens, Anthony (1984) The Constitution of Society: Outline of the Theory of Structuration. Cambridge, UK: Polity Press.

Grafton, Anthony (1994) The footnote from de Thon to Ranke. In Proof and Persuasion in History. Edited by S. Marchand and A. Grafton. Germany: Beiheft. pp. 53-76.

Hinds, John (1987) Reader versus writer responsibility: a new typology. In Connor and Kaplan (1987: 141-152).

Honey, John (1994) Review of Phillipson's Linguistic Imperialism. RASK, 1, 117-121.

Janapoulos, Michael (1995) Writing across the curriculum, writing proficiency exams, and the NNS college student. Journal of Second Language Writing, 4, 43-50.

Kachru, Braj B. (1994) Englishization and contact linguistics. World Englishes, 13, 135-54.

Kachru, Yamuna (1995) Cultural meaning and rhetorical styles: toward a framework for contrastive rhetoric. In Principle and Practice in Applied Linguistics: Studies in Honour of H. G. Widdowson. Edited by Guy Cook and Barbara Seidlhofer. Oxford: Oxford University Press. pp. 171-184.

Lemke, Jay (1994) Genre as a strategic resource. Paper presented at NCTE, Orlando, FL (November).

Mauranen, Anna (1993a) Cultural Differences in Academic Rhetoric. Frankfurt: Peter Lang.

Mauranen, Anna (1993b) Cultural differences in academic discourse - problems of a linguistic and cultural minority. In The Competent Intercultural Communicator: A AFinLA Yearbook. Edited by L. Lofman et al. Helsinki: AFinLA. pp. 157-174.

Pennycook, Alastair (1994) The Cultural Politics of English as an International Language. Harlow,UK: Longman.

Ongstad, Sigmund (1992) The definition of genre and the didactics of genre. Paper presented at the Rethinking Genre Seminar. Ottawa, April.

Phillipson, Robert (1992) Linguistic Imperialism. Oxford: Oxford University Press.

Santos, Terry (1992) Ideology and composition: L1 and ESL. Journal of Second Language Writing, 1, 1-15.

Schryer, Catharine F. (1994) The lab vs. the clinic: sites of competing genres. In Genre and the New Rhetoric. Edited by Aviva Freedman and Peter Medway. Bristol, PA: Taylor and Francis. pp. 105-124.

Swales, John M. (1990) Genre Analysis: English in Academic and Research Settings. Cambridge: Cambridge University Press.

Swales, John M. (1996) Occluded genres in the academy: the case of the submission letter. In Academic Writing: Intercultural and Textual Issues. Edited by Eija Ventola and Anna Mauranen. Amsterdam: John Benjamins. pp. 45-58.

Swales, John M. and Luebs, Margaret (1995) Toward Textography. In Writing in Academic Contexts. Edited by Britt-Louise Gunnarsson and Ingegerd Bäcklund. FUMS; Uppsala. pp. 12-29.

Wayt Gibbs, W. (1995) Lost science in the Third World. Scientific American, August. pp. 92-99.

(Received 20 February 1997.) 